\title{
Preconditioning with a Novel Metallopharmaceutical NO Donor in Anesthetized Rats Subjected to Brain Ischemia/Reperfusion
}

\author{
Marcio Wilker Soares Campelo • Reinaldo Barreto Oriá • Luiz Gonzaga de França Lopes • \\ Gerly Anne de Castro Brito - Armenio Aguiar dos Santos - Raquel Cavalcante de Vasconcelos • \\ Francisco Ordelei Nascimento da Silva $\cdot$ Beatrice Nuto Nobrega • \\ Moisés Tolentino Bento-Silva $\cdot$ Paulo Roberto Leitão de Vasconcelos
}

Received: 24 August 2011/Revised: 19 November 2011/ Accepted: 29 November 2011/Published online: 10 December 2011

(C) Springer Science+Business Media, LLC 2011

\begin{abstract}
Rut-bpy is a novel nitrosyl-ruthenium complex releasing NO into the vascular system. We evaluated the effect of Rut-bpy $(100 \mathrm{mg} / \mathrm{kg})$ on a rat model of brain stroke. Forty rats were assigned to four groups (Saline solution [SS], Rut-bpy, SS+ischemia-reperfusion [SS+I/ $\mathrm{R}]$ and Rut-bpy+ischemia-reperfusion [Rut-bpy+I/R]) with their mean arterial pressure (MAP) continuously monitored. The groups were submitted (SS+I/R and Rutbpy $+\mathrm{I} / \mathrm{R}$ ) or not (SS and Rut-bpy) to incomplete global brain ischemia by occlusion of the common bilateral carotid arteries during $30 \mathrm{~min}$ followed by reperfusion for further $60 \mathrm{~min}$. Thirty minutes before ischemia, rats were treated pairwise by intraperitoneal injection of saline solution or Rut-bpy. At the end of experiments, brain was removed for triphenyltetrazolium chloride staining in order
\end{abstract}

M. W. S. Campelo $(\bowtie) \cdot$ P. R. L. de Vasconcelos Department of Surgery, Federal University of Ceará,

R. Professor Costa Mendes, 1608/3 Andar, Fortaleza,

CE CEP:60430-140, Brazil

e-mail: marciowilker@bol.com.br

R. B. Oriá · G. A. C. Brito - M. T. Bento-Silva

Department of Morphology, Federal University of Ceará,

Fortaleza, Brazil

L. G. de França Lopes · F. O. N. da Silva

Department of Organic and Inorganic Chemistry,

Federal University of Ceará, Fortaleza, Brazil

\section{A. A. dos Santos}

Department of Physiology and Pharmacology,

Federal University of Ceará, Fortaleza, Brazil

R. C. de Vasconcelos - B. N. Nobrega

Student of the Medical School, Federal University of Ceará,

Fortaleza, Brazil to quantify the total ischemic area. In a subset of rats, hippocampus was obtained for histopathology scoring, nitrate and nitrite measurements, immunostaining and western blotting of the nuclear factor- $\kappa \mathrm{B}(\mathrm{NF}-\kappa \mathrm{B})$. Rutbpy pre-treatment decreased MAP variations during the transition from brain ischemia to reperfusion and decreased the fractional injury area. Rut-bpy pre-treatment reduced NF- $\kappa \mathrm{B}$ hippocampal immunostaining and protein expression with improved histopathology scoring as compared to the untreated operated control. In conclusion, Rut-bpy improved the total brain infarction area and hippocampal neuronal viability in part by inhibiting NF- $\kappa \mathrm{B}$ signaling and helped to stabilize the blood pressure during the transition from ischemia to reperfusion.

Keywords Brain - Ischemia-reperfusion - Nitric oxide · Nitrosyl-ruthenium complex $\cdot$ Nuclear factor- $\kappa \mathrm{B}$

\section{Introduction}

Cerebral ischemia/reperfusion (I/R) is caused by a transient or permanent reduction in the brain blood flow and constitutes a major cause of human morbidity and mortality [1].

The pathophysiological process of brain I/R-induced neuronal damage is complex and involves nitric oxide (NO) pathways [2-5]. NO is a free radical associated with a multitude of physiological functions.

Nitric oxide (NO) produced by endothelial nitric oxidase (eNOS) reduces apoptosis and confers protection against stroke, whereas pathological concentrations of NO from inducible iNOS and neuronal nitric oxidase (nNOS) lead to apoptosis and are neurotoxic [6-8].

Nitric oxide (NO) donors are pharmacologically active substances that release NO into biological systems, 
spontaneously or by induction, eliciting a response similar to that of endogenous NO or compensating for endogenous NO deficiency [9-11]. The administration of NO donors has broadened therapy strategies for neuronal protection, by improving vasodilation and blood perfusion to the brain tissue [12-14], especially when the blood flow and vascular endothelial system are compromised.

Over the past years much attention has been given to nitrosyl-ruthenium complexes and their potential pharmacological use, especially due to their rapid NO release [15] as well as low level of toxicity [16-18]. Several ruthenium compounds have been synthesized and purified, but so far none has been tested in studies of experimental brain ischemia and reperfusion.

The NO donor-Rut-bpy (cis-[Ru(bpy) $\left.\left.{ }_{2}\left(\mathrm{SO}_{3}\right)(\mathrm{NO})\right] \mathrm{PF}_{6}\right)$ can release nitric oxide through chemical, electro and photochemical reactions [11]. In biological medium, this complex can release NO activated by biological reducing agents [19].

Rut-bpy is a potent vasodilator capable of releasing intracellular NO and activating guanylate cyclase [20]. Besides producing higher maximum relaxation in aortic rings than sodium nitroprusside at similar molar basis, Rutbpy is associated with higher levels of NO release without being photosensitive or releasing cyanide [20, 21].

In order to resemble a clinical condition prior to cerebrovascular surgery, when there is an increased risk of perioperative ischemia/reperfusion and stroke, we evaluate the preconditioning effect of a novel nitrosyl-ruthenium complex (Rut-bpy) on the total brain ischemic area and on variations of the mean arterial blood pressure following bilateral carotid occlusion and reperfusion in Wistar rats. In addition, we addressed whether this novel nitrosyl-ruthenium complex could protect hippocampal neurons with less $\mathrm{NF}-\kappa \mathrm{B}$ hippocampal expression.

\section{Methods}

All surgical procedures and animal handling were conducted in accordance with the Guide for the Care and Use of Laboratory Animals from the Brazilian College of Animal Experimentation, after approval by the local ethics committee (protocol \#62). The study was designed to minimize the number of animals required for the experiments.

Male Wistar rats (Rattus norvegius albinus), weighing 280-300 g were under standard housing conditions with free access to water and chow, and were randomly assigned to four groups of fifteen animals each: saline solution (SS); Rut-bpy; SS followed by ischemia-reperfusion $(\mathrm{SS}+\mathrm{I} / \mathrm{R})$; Rut-bpy followed by ischemia-reperfusion (Rut-bpy+I/R).
Anesthesia and Blood Pressure Monitoring

Rats were anesthetized by an intramuscular injection of xylazine $(10 \mathrm{mg} / \mathrm{kg})$ and ketamine $(90 \mathrm{mg} / \mathrm{kg})$ solution. A polyethylene catheter filled with heparinized saline solution was introduced directly into the femoral artery and connected to a pressure transducer for continuous monitoring of mean arterial pressure (MAP) during the course of the experiment. The rectal temperature was also monitored with a digital thermometer and maintained at $35-37^{\circ} \mathrm{C}$.

\section{Drug}

Rut-bpy (cis-[Ru(bpy) $\left.\left.)_{2}\left(\mathrm{SO}_{3}\right)(\mathrm{NO})\right] \mathrm{PF}_{6}\right)$ was synthesized and purified at the Department of Organic and Inorganic Chemistry of the Federal University of Ceará (Brazil), following procedures described elsewhere [14]. Thirty minutes before induction of ischemia, Rut-bpy (prepared from a working solution of $1.95 \mathrm{mM}$ ) was administered intraperitoneally at a dose of $0.15 \mathrm{mmol} / \mathrm{kg}$ (equivalent to $100 \mathrm{mg} / \mathrm{kg}$ ). This dosage was based on previous experiments, which showed low toxicity to rats [17] and benefits in a model of septic shock [15].

Induction of Ischemia and Reperfusion

After anesthesia and femoral artery cannulation, experimental rats were submitted to anterior cervical incision followed by dissection of the common carotid arteries around the internal and external artery bifurcation (i.e., the clamping site), as described elsewhere [21-23]. The rats assigned to SS or Rut-bpy groups were spared of further interventions but subsequently euthanized. The rats assigned to ischemia-reperfusion were submitted to a similar bilateral occlusion of the carotid arteries for $30 \mathrm{~min}$, followed by release of the vascular clamp and free cerebral blood flow for $60 \mathrm{~min}$ and then at the desired time after the onset of reperfusion, animals were sacrificed and sampled (brain) for 2\% 2,3,5-triphenyl-tetrazolium chloride (TTC) stain, hippocampal histopathology, NO metabolite measurement, and NF- $\kappa \mathrm{B}$ immunolabeling, as described below.

\section{TTC Stain}

Following decapitation, the brain was excised and $2 \mathrm{~mm}$ coronal sections were made in segments 0 to $+6 \mathrm{~mm}$ of the Bregma, according to the stereotaxic coordinates [24]. Each section was incubated in saline solution containing $1 \%$ of $\mathrm{TTC}$ for $30 \mathrm{~min}$ at $37^{\circ} \mathrm{C}$ and repositioned after $15 \mathrm{~min}$. Next, the slices were rinsed three times for $1 \mathrm{~min}$ with normal saline solution to remove excess TTC, as previously described [25]. Areas not stained red by TTC were considered as damaged tissue [26-29]. The slices 
were scanned and digitized in high resolution (600 dpi) without color correction, image enhancement or linear gain [30]. The area of tissue damage of each section was calculated with the morphometry software UTHSCSA (The University of Texas Health Science Center at San Antonio). The damaged area/total area ratio was calculated for each section, and the sum of the ratios of the four sections from each brain (within the selected stereotactic coordinates) was taken as the total incidence of tissue damage of each animal.

\section{Hippocampus Histopathology}

The brain was removed from the skull and four coronal sections were made ( $2 \mathrm{~mm}$ each) and then immersion fixed in formalin for $24 \mathrm{~h}$ before being transferred to $70 \%$ ethanol solution, further processed, embedded in paraffin, and cut to generate $5-\mu \mathrm{m}$-thick coronal sections onto slides. The slides were stained using hematoxylin and eosin. The extent of the hippocampus damage was assessed by a neuropathologist, blindly, using a light microscope (Olympus, 400 $\times$ ), the number of pink acidophilic dead neurons (red neurons) were counted, as described by Kaku et al. [31]. Neuronal damage in the $\mathrm{Ca} 1, \mathrm{Ca} 2 / \mathrm{Ca} 3$ areas of the hippocampus was expressed as the percentage of dead cells in the total $400 \times$ microscope-field cell population.

\section{Immunohistochemistry}

Immunohistochemistry for NF- $\kappa \mathrm{B}$ p50 (NLS) was performed on brain tissue using the streptavidin-biotin-peroxidase method in formalin-fixed, paraffin-embedded tissue sections ( $4 \mu \mathrm{m}$ thick), mounted on poly-L-lysinecoated microscope slides. The sections were deparaffinized and rehydrated through xylene and graded alcohols. After antigen retrieval, endogenous peroxidase was blocked (15 min) with 3\% (vv-1) hydrogen peroxide and washed in phosphate-buffered saline (PBS). Sections were incubated overnight $\left(4^{\circ} \mathrm{C}\right)$ with primary rabbit anti-NF- $\kappa \mathrm{B}$ antibody diluted 1:200 in PBS plus bovine serum albumin (PBSBSA). The slides were then incubated with biotinylated goat anti-rabbit; diluted 1:400 in PBS-BSA. After washing, the slides were incubated with avidin-biotin-horseradish peroxidase conjugate (Strep ABC complex by Vectastain ${ }^{\circledR}$ $\mathrm{ABC}$ Reagent and peroxidase substrate solution) for 30 min, according to the Vectastain protocol. NF- $\kappa \mathrm{B}$ was visualized with the chromogen $3,3^{\prime}$ diaminobenzidine (DAB). Negative control sections were processed simultaneously as described above but with the first antibody being replaced by PBS-BSA 5\%. None of the negative controls showed NF- $\kappa \mathrm{B}$ immunoreactivity. Slides were counterstained with Harry's hematoxylin, dehydrated in a graded alcohol series, cleared in xylene and cover slipped.

\section{Western Blotting}

Immediately after reperfusion time, total hippocampus was carefully removed and rapidly frozen in liquid nitrogen and stored at $-80^{\circ} \mathrm{C}$. Thawed specimens were pulverized with an electric homogenizer (ultra-Turrax homogenizer, Sigma, St. Louis, MO, USA), containing lysis buffer and then transferred to test tubes with a protease inhibitor cocktail and centrifuged at $14,000 \mathrm{rpm}$. Supernatants were assayed using the bicinchoninic acid method, BCA Protein Assay Kit (Pierce, Rockford, IL, USA) to standardize $50 \mu \mathrm{g}$ of protein product. Samples were loaded into $15 \%$ denaturating polyacrylamide mini gels (Bio-Rad, Hercules, CA, USA), and gels were transferred overnight and then blotted onto nitrocellulose membranes. Membranes were incubated with rabbit anti-NF- $\kappa \mathrm{B}$ antibody at dilution of 1:300, (Santa Cruz Biotechnology, CA, USA) for $2 \mathrm{~h}$ and then rinsed three times in rinsing buffer, then incubated in a secondary antibody and rinsed as described above. Each membrane was washed and exposed to Kodak X-Omat AR film (Kodak, Rochester, NY, USA). Densitometry results were normalized with $\beta$-actin, as an internal control.

\section{Measurement of NO Metabolites in Hippocampus}

Immediately after reperfusion time, total hippocampus was carefully removed and rapidly frozen in liquid nitrogen and stored at $-80^{\circ} \mathrm{C}$ until $\mathrm{NO}$ metabolite analyses. Briefly, hippocampus tissue was minced and homogenized in sucrose buffer. Homogenates were centrifuged at $1,000 \times g$ for $10 \mathrm{~min}$. Supernatants were incubated in a microplate with nitrate reductase $\left(0.016 \mathrm{U}^{*} \mathrm{well}^{-1}\right)$ for $12 \mathrm{~h}$ to convert $\mathrm{NO}_{3}-\mathrm{NO}_{2}$. The accumulation of nitrite $\left(\mathrm{NO}_{2}\right)$ in the supernatant, an indicator of the production of $\mathrm{NO}$, was determined with a colorimetric assay with Greiss reagent $(0.1 \%$ N-(1-naphthyl) ethylenediamine dihydrochloride, $1 \%$ sulfanilamide, and $2.5 \%$ phosphoric acid) as described by Green et al. [32]. Equal volumes of supernatant and Greiss reagent were mixed; the mixture was incubated for $10 \mathrm{~min}$ at room temperature in the dark. Calibration curves were made with sodium nitrite $(5-50 \mathrm{M})$ in distilled water. Absorbance was measured in an ELISA plate reader at $540 \mathrm{~nm}$ by a spectrophotometer. Results were expressed as micromoles of nitrite using the internal standard curve.

\section{Statistical Analysis}

Data (TTC and western blotting) were expressed as mean \pm SD. After a Kolmogorov-Smirnov test of normality, data were submitted to one-way analysis of variance followed by Tukey's multiple comparison test. MAP was expressed as mean + SD. MAP data were submitted to two-way analysis of variance followed by Bonferroni post-tests. Nonparametric data (histopathology) were expressed as medians and 
percentiles (25-75), and analyzed by Mann-Whitney test. The level of statistical significance was set at $5 \%$.

\section{Results}

Ischemia-Reperfusion Effect on Cerebral Tissue

The amount of TTC unstained cerebral tissue was greater in the $\mathrm{SS}+\mathrm{I} / \mathrm{R}$ group (administration of SS prior to ischemia-reperfusion) than in the group receiving SS alone (damaged/total
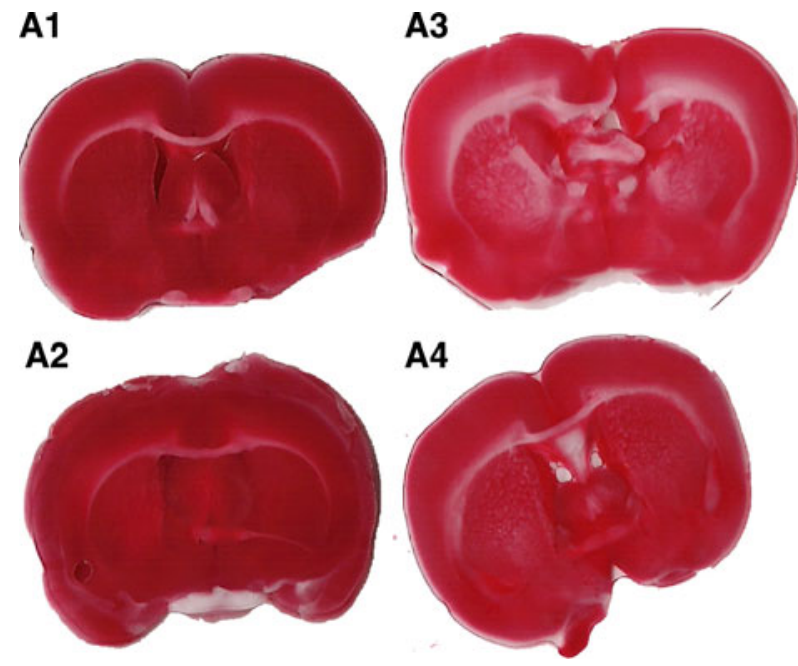

area ratio, $P<0.01$ ) (Fig. 1). The histopathological examination (H\&E) of target hippocampus regions also revealed a greater number of damaged nerve cells (red nerve cells) in the $\mathrm{SS}+\mathrm{I} / \mathrm{R}$ group than in the group receiving $\mathrm{SS}$ alone $(P<0.02)$ (Figs. 2, 3).

\section{Neuroprotective Effect of Rut-bpy}

The total TTC unstained area was significantly smaller in the Rut-bpy+I/R group as opposed to the $\mathrm{SS}+\mathrm{I} / \mathrm{R}$ group

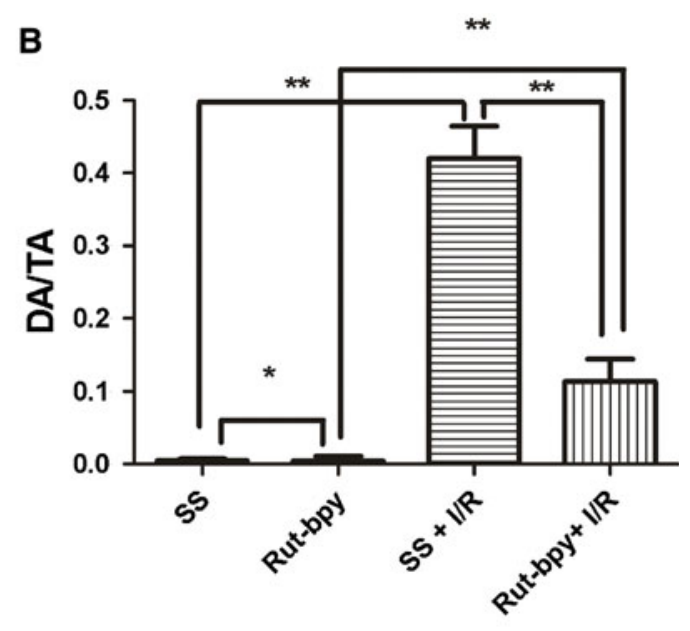

Fig. 1 A Representative TTC-stained-coronal brain sections from SS (A1), Rut-bpy (A2), SS+I/R (A3), and Rut-bpy+I/R (A4). B Damaged area/total area ratio (DA/TA) of rat brain sections (sum of the section ratios) - TTC stain. $* * P<0.01$ for $\mathrm{SS}$ versus $\mathrm{SS}+\mathrm{I} / \mathrm{R}, \mathrm{SS}+\mathrm{I} / \mathrm{R}$ versus Rut-bpy $+\mathrm{I} / \mathrm{R} ; * P>0.05$. $\mathrm{SS}=$ saline solution; Rut-bpy $=$ cis- $\left[\mathrm{Ru}(\mathrm{bpy})_{2}\left(\mathrm{SO}_{3}\right)(\mathrm{NO})\right] \mathrm{PF}_{6} ; \mathrm{I} / \mathrm{R}=$ ischemia/reperfusion
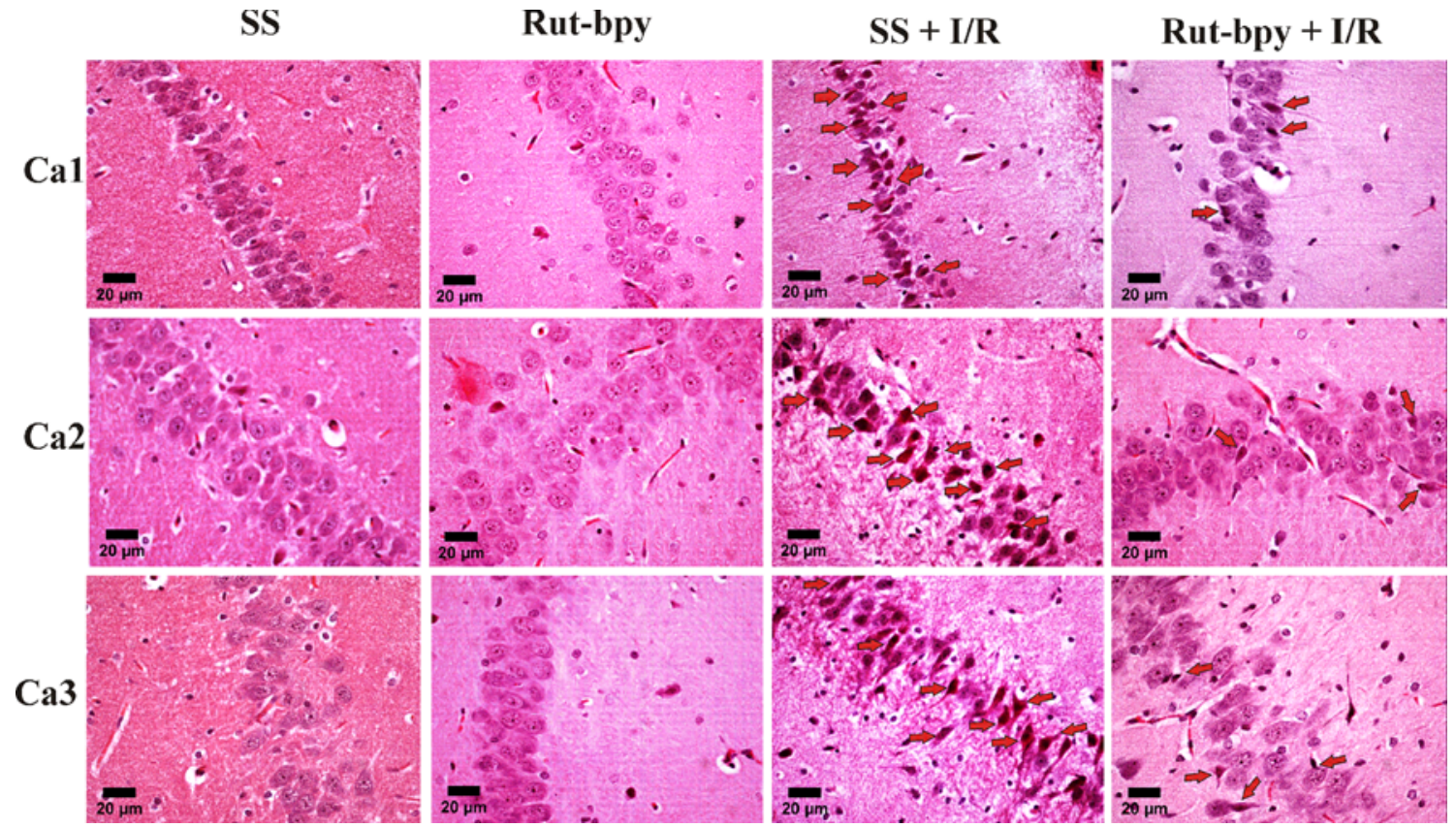

Fig. 2 Histological changes in the CA1, CA2, and CA3 hippocampal regions. Representative hematoxylin and eosin-stained pyramidal neurons from SS, Rut-bpy, SS+I/R, and Rut-bpy+I/R groups.

Magnification $\times 400 . \quad$ SS $=$ saline $\quad$ solution; $\quad$ Rut-bpy $=$ cis- $[\mathrm{Ru}$ (bpy) $\left.)_{2}\left(\mathrm{SO}_{3}\right)(\mathrm{NO})\right] \mathrm{PF}_{6} ; \mathrm{I} / \mathrm{R}=$ ischemia/reperfusion; Arrows indicate red neurons (acidophilic dead neurons) 


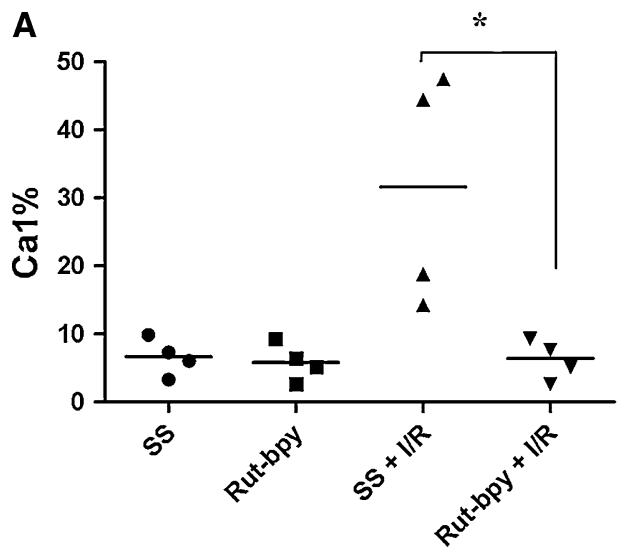

Fig. 3 Percentage of dead cells in the total pyramidal cell population counted from high-magnified fields of hippocampal sections. a Percentage of dead cells in the CA1 total pyramidal cell population counted from high-magnified fields. $* P<0.05$ b Percentage of dead

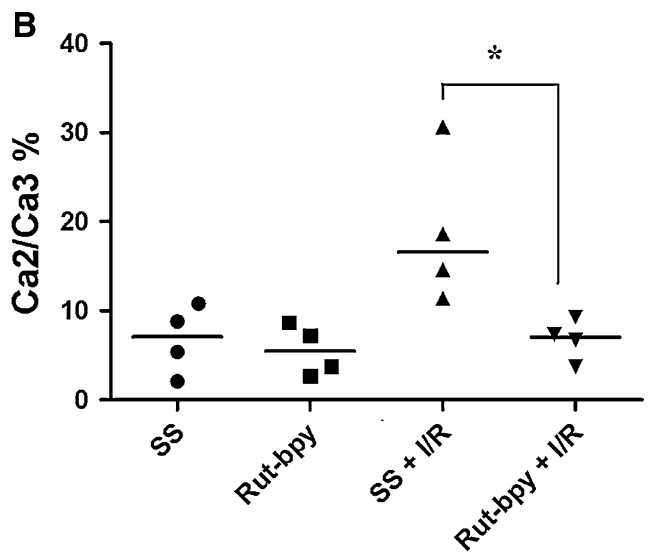

cells in the CA2 plus CA3 total pyramid cell population counted from high-magnified fields, $* P<0.05$ (group $\mathrm{SS}+\mathrm{I} / \mathrm{R}$ vs. Rut-bpy $+\mathrm{I} / \mathrm{R}$ ). $\mathrm{SS}=$ saline solution; Rut-bpy $=$ cis- $\left[\mathrm{Ru}(\mathrm{bpy})_{2}\left(\mathrm{SO}_{3}\right)(\mathrm{NO})\right] \mathrm{PF}_{6} ; \mathrm{I} / \mathrm{R}=$ ischemia/reperfusion
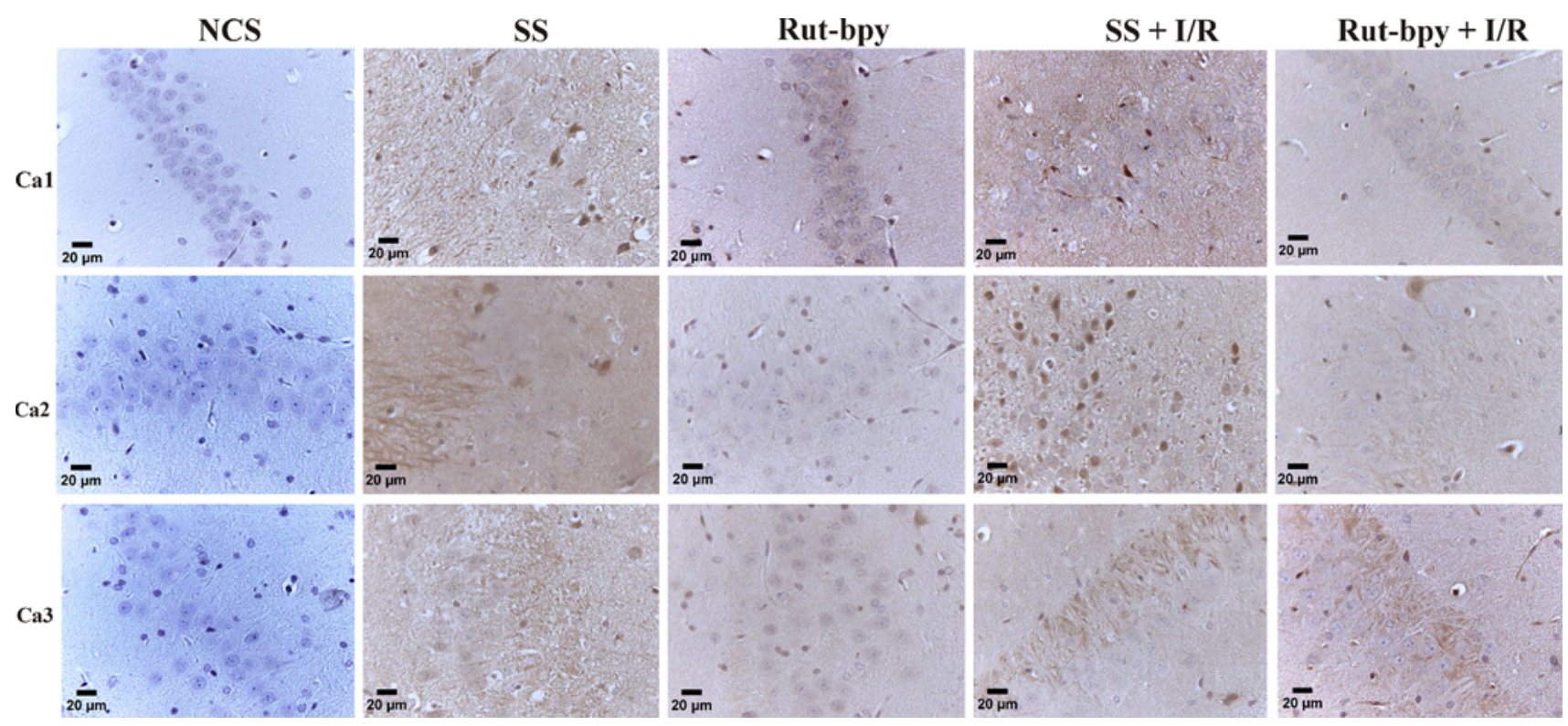

Fig. 4 Representative hippocampal NF- $\kappa$ B p50 (NLS) immunohistochemistry in CA1, CA2 and CA3 regions obtained from Rut-bpy, $\mathrm{SS}+\mathrm{I} / \mathrm{R}$, and Rut-bpy $+\mathrm{I} / \mathrm{R}$ groups. Cells with brown/dark staining are $\mathrm{NF}-\kappa \mathrm{B}$-positive. None of the negative controls sections showed

$(0.11 \pm 0.03$ vs. $0.42 \pm 0.04 ; P<0.01)$ (Fig. 1$)$. The SS and Rut-bpy groups did not differ significantly $(P>0.05)$. However, we found differences between SS versus Rutbpy $+\mathrm{I} / \mathrm{R}$ and Rut-bpy versus Rut-bpy $+\mathrm{I} / \mathrm{R}$ groups, $P<0.01$.

The histopathological examination (H\&E) of the hippocampal regions revealed a significantly lower number of damaged neuronal cells (eosinophilic neuron) in the Rutbpy $+\mathrm{I} / \mathrm{R}$ group (Ca1: 6.42, range 3.26-8.92; Ca2/Ca3: 7.05, range $4.50-8.81$ ) as compared with the $\mathrm{SS}+\mathrm{I} / \mathrm{R}$ group (Ca1: 31.60 , range $15.40-46.68 ; \mathrm{Ca} 2 / \mathrm{Ca} 3$ : 16.60, range
NF- $\kappa \mathrm{B}$ immunoreactivity. Magnification $\times 400$. SS $=$ saline solution; Rut-bpy $=$ cis- $\left[\mathrm{Ru}(\mathrm{bpy})_{2}\left(\mathrm{SO}_{3}\right)(\mathrm{NO})\right] \mathrm{PF}_{6} ; \quad \mathrm{I} / \mathrm{R}=$ ischemia/reperfusion; NCS $=$ negative control sections (Color figure online)

12.22-27.64) $(P<0.02)$ (Figs. 2, 3). SS and Group Rut-bpy groups did not differ significantly $(P>0.05)$ (Figs. 2,3$)$.

Furthermore, the NF- $\kappa \mathrm{B}$ p50 (NLS) immunohistochemical staining was less striking in Rut-bpy $+\mathrm{I} / \mathrm{R}$ than in the SS+I/R group (Fig. 4).

\section{Mean Blood Pressure Monitoring}

During the first $15 \mathrm{~min}$ of reperfusion, blood pressure variation was significantly smaller in the Rut-bpy $+\mathrm{I} / \mathrm{R}$ group as compared with the $\mathrm{SS}+\mathrm{I} / \mathrm{R}$ group $(6.49 \pm$ 


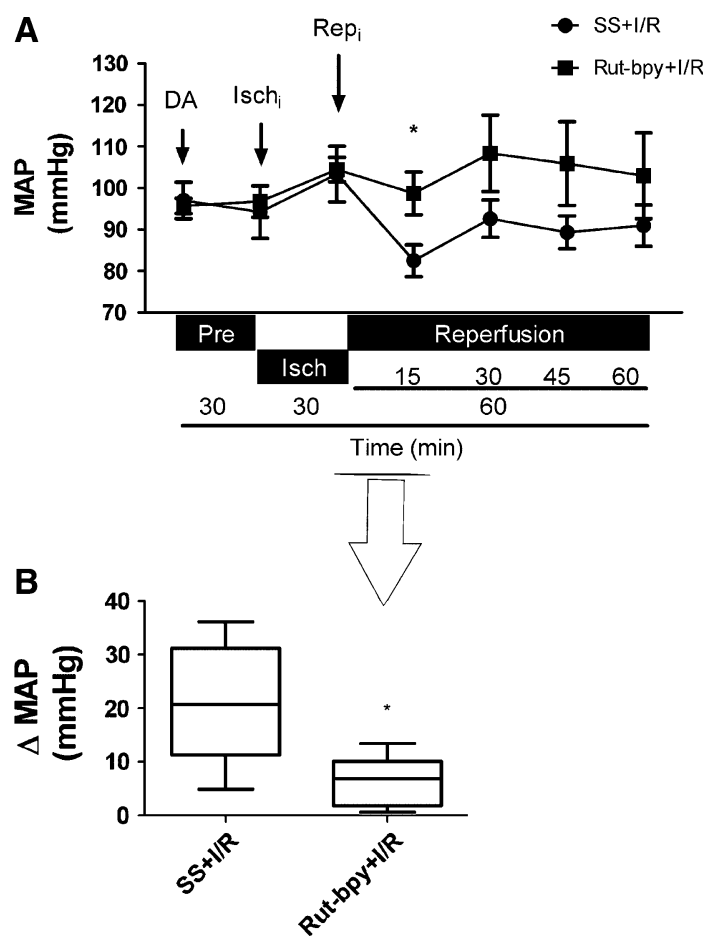

Fig. 5 a Mean arterial pressure (MAP) from experimental rats during induced-ischemia (30 $\mathrm{min})(P>0.05, \mathrm{SS}+\mathrm{I} / \mathrm{R}$ vs. Rut-bpy $+\mathrm{I} / \mathrm{R})$ and during reperfusion $(* P<0.05, \mathrm{SS}+\mathrm{I} / \mathrm{R}$ vs. Rut-bpy $+\mathrm{I} / \mathrm{R})$. b Differences in mean arterial pressure ( $\triangle \mathrm{MAP})$ between ischemia $(30 \mathrm{~min})$ and the first $15 \mathrm{~min}$ of reperfusion. $* P<0.05$ for $\mathrm{SS}+\mathrm{I} / \mathrm{R}$ versus Rut-bpy $+\mathrm{I} / \mathrm{R} . \mathrm{SS}=$ saline solution; Rut-bpy $=$ cis- $\left[\mathrm{Ru}(\mathrm{bpy})_{2}\left(\mathrm{SO}_{3}\right)(\mathrm{NO})\right] \mathrm{PF}_{6}$; Isch $_{\mathrm{i}}=$ beginning of the isquemia; $\operatorname{Rep}_{\mathrm{i}}=$ beginning of the reperfusion; $\mathrm{DA}=$ drug administration; Pre = preconditioning with Rut-bpy (Rutbpy $+\mathrm{I} / \mathrm{R}$ group) or $\mathrm{SS}(\mathrm{SS}+\mathrm{I} / \mathrm{R}$ group$) ; \mathrm{Rep}=$ reperfusion phase

$4.6 \mathrm{mmHg}$ vs. $20.89 \pm 11.77 \mathrm{mmHg} ; P<0.04$ ) (Fig. 5). The groups did not differ significantly during the ischemia phase $(P>0.05)$.

\section{NO Metabolite Concentration}

We found reductions in the nitrate concentration in the SS $+\mathrm{I} / \mathrm{R}$ hippocampus when compared with SS (these result was in agreement with the reduced level of NO reported earlier in cerebral tissues after I/R injury $[12,33]$. The Rutbpy $+\mathrm{I} / \mathrm{R}$ group showed greater hippocampal nitrate concentration than the $\mathrm{SS}+\mathrm{I} / \mathrm{R}$ group. However, SS versus Rut-bpy $+\mathrm{I} / \mathrm{R}$ did not differ significantly $(P>0.05)$. The group Rut-bpy showed the highest level of NO metabolites than all the others groups $(P<0.01$; Rut-bpy vs. SS, $\mathrm{SS}+\mathrm{I} / \mathrm{R}$, Rut-bpy $+\mathrm{I} / \mathrm{R}$ ) (Fig. 6).

\section{Hippocampal Expression of NF- $\kappa \mathrm{B}$}

As shown in Fig. $7 \mathrm{a}, \mathrm{b}, \mathrm{NF}-\kappa \mathrm{B}$ densitometry in SS $+\mathrm{I} / \mathrm{R}$ group was markedly increased. Preconditioning of Rut-bpy reduced NF- $\kappa$ B protein levels in the hippocampus.

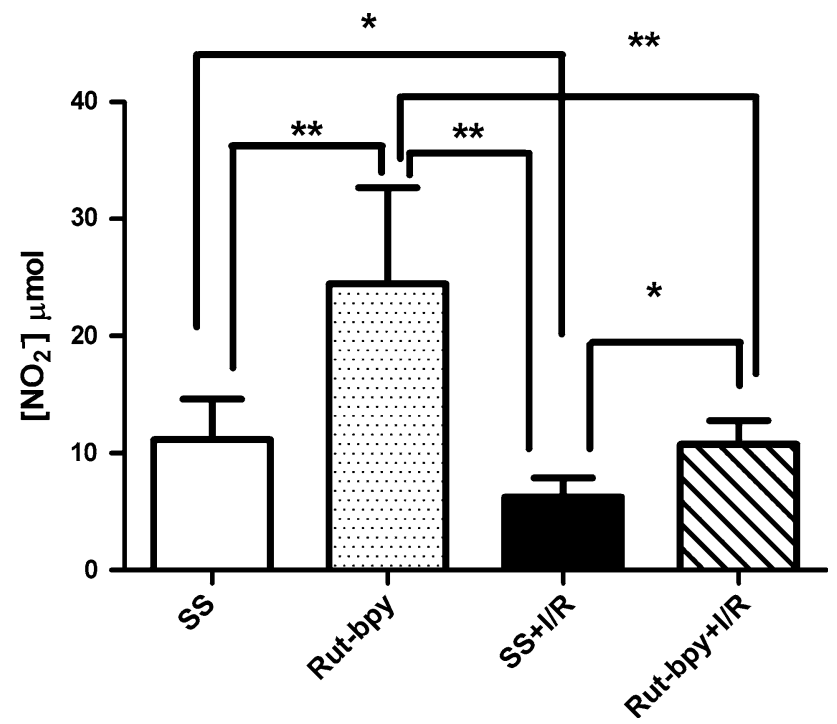

Fig. 6 Effect of Rut-bpy preconditioning on $\mathrm{NO}_{2}{ }^{-}$levels in the hippocampus after $30 \mathrm{~min}$ of ischemia and $60 \mathrm{~min}$ of reperfusion. Results are expressed as $\mathrm{NO}_{2}{ }^{-}$tissue level $(\mu \mathrm{g} / \mathrm{ml})$ and data are presented as mean $\pm \mathrm{SD}$ from duplicate measurements in two different sets. $* P<0.05, * * P<0.01$

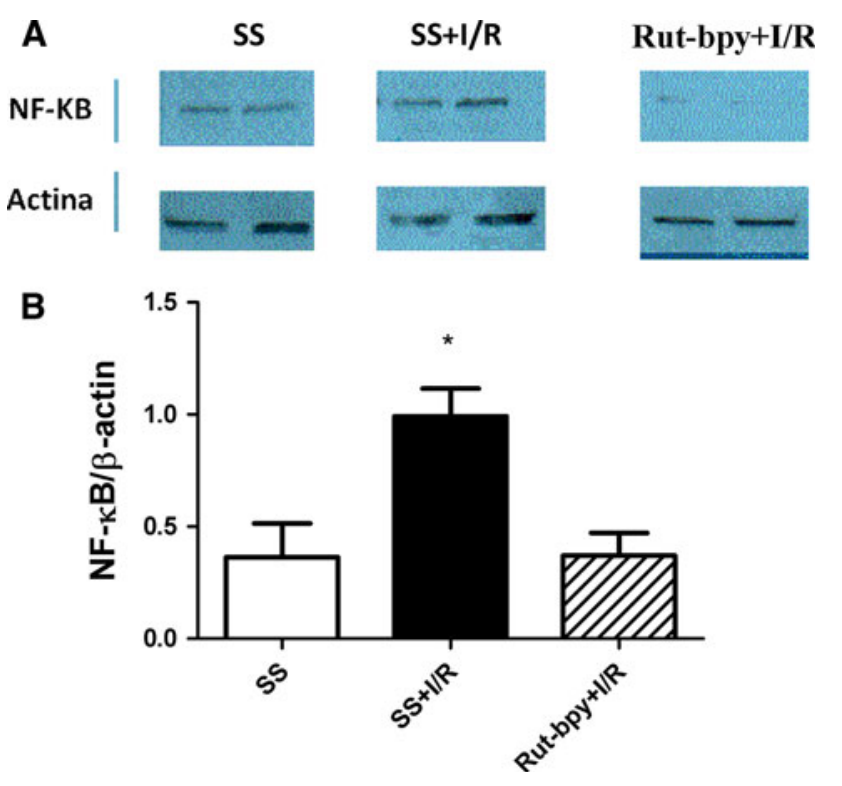

Fig. 7 Rut-bpy preconditioning decreased NF- $\kappa \mathrm{B}$ expression in hippocampus. a Representative Western blot analysis. b Quantitative analysis of the protein levels of NF- $\kappa \mathrm{B}$ from four rats in each group. The data are normalized to the loading control $\beta$-actin. Values are expressed as mean $\pm \mathrm{SD}(n=4)$. $* P<0.05$, as compared $\mathrm{SS}+\mathrm{I} / \mathrm{R}$ with SS or Rut-bpy+I/R

\section{Discussion and Conclusions}

Over the past decade much has been discovered concerning the pathophysiology of cerebral ischemia/reperfusion [34-36] and many new forms of treatment have been 
proposed based on the pharmaceutical effects of nitric oxide made available by NO donors [11-13, 37, 38] or NO synthase (NOS) inhibitors [4, 11, 39, 40].

The only metallopharmaceutical NO donor used clinically today is sodium nitroprusside, with a disadvantage to be photosensitive and to release cyanide. In contrast, the newly discovered nitrosyl-ruthenium complex Rut-bpy (cis- $\left.\left[\mathrm{Ru}(\mathrm{bpy})_{2}\left(\mathrm{SO}_{3}\right)(\mathrm{NO})\right] \mathrm{PF}_{6}\right)$ has neither of these disadvantages besides being soluble in water [14].

To the best of our knowledge, the present study is the first to demonstrate that Rut-bpy, with a dose smaller than the lethal dose $\left(\mathrm{LD}_{50}\right)$ used elsewhere [17], can markedly reduce damage to hippocampal neurons caused by ischemia/reperfusion, with relatively small changes in blood pressure during transition from ischemia to reperfusion.

To evaluate the effect of pharmacological preconditioning on cerebral ischemia/reperfusion in anesthetized rats, the animals were treated with a combination of xylazine and ketamine at a dose capable of reducing cerebral blood flow and the oxygen partial pressure in the cerebral tissue [41] and in regard to the body temperature, Stein [42] did no found differences in body temperature values when compared with the control group in their studies in rats under xylazine and ketamine anesthesia. In this model, previously used by a number of researchers $[21,22,24,36,43,44]$, damage to the cerebral tissue is caused by the occlusion of the common carotid artery. In the current study, however, the two carotid arteries were occluded simultaneously to induce ischemia and unblocked to restore blood flow. The model is easy to use and effectively impairs blood supply to the brain [44, 45] and reduces ATP-forming oxidative phosphorylation [21]. In addition, it simulates the consequences of perioperative ischemia/reperfusion when the blood flow in the carotid artery needs to be interrupted, as during surgery for tumors, aneurisma and post-trauma correction of the carotids.

Rut-bpy has been shown to induce relaxation in vitro in aortic rings (without endothelium) by the direct release of NO into the smooth musculature [18]. In the present study, using an incomplete global ischemia model in vivo, Rut-bpy reduced neuronal damage caused by ischemia/reperfusion. The evaluation took into account the intensity of staining with TTC - a proton acceptor for many pyridine nucleotidelinked dehydrogenases which, along with the cytochromes, form an integral part of the inner mitochondrial membrane and make up the electron transport chain [46], thereby reflecting mitochondrial functional activity [29]. However, the finding of the transient reduction of dehydrogenase activity is uncertain after a short period of reperfusion [47, 48]. Therefore, in addition to TTC, we analyze the hippocampus tissue, a well-known vulnerable brain region to the ischemic-reperfusion insult [23].
In our studies, histopathological examination of the hippocampus provided clear evidence of the protective effect of Rut-bpy when administered in vivo prior to ischemia/reperfusion (Figs. 2, 3). It also suggests that NF- $\kappa \mathrm{B}$ downregulation played a role in rut-bpy-related hippocampal neuroprotection (Figs. 4, 7). Similar findings have been reported with $\mathrm{NO}$ donors in focal ischemia models [11].

The observed neurovascular protective mechanism of NO indicates that NO donors are most effective when an appropriate drug amount is delivered by a suitable source at the right time window and in suitable environment $[12,49]$.

There is much evidence to support that brain ischemia and reperfusion can lead to dysfunction in the cerebral vascular endothelium, possibly due to an increased production of vasoconstrictors and/or reduced availability of vasodilators, like NO [50]. In fact, NO donors can reduce tissue damage following brain ischemia and reperfusion $[3,11,13,37]$ through vasodilation and increased cerebral blood flow [11]. The NO donor Rut-bpy has been shown to induce vasodilation through cGMP [18] and show benefits in amplifying hippocampal evoked potentials in vitro, directly correlated with NO release [51]. In the present work, as expected, we found increased NO metabolites in hippocampus, confirming the NO release and metabolization.

Due to their well-developed circle of Willis, rats have their cerebral blood supply reduced by $50 \%$ only when submitted to ischemia through the clamping of both carotids [44]. Thus, the presence of a vasodilator, such as NO, favors blood flow in any unoccluded vessels of the circle of Willis (vertebral arteries). In addition, studies on cerebral angiography have shown that even with a thoroughly cauterization of the vertebral arteries, a number of unoccluded vessels may be left and the brain tissue may receive blood from the collateral circulation even when all extracranial cerebral vessels have been occluded [52], thus justifying the use of $\mathrm{NO}$ to increase blood flow.

De La Torre and Aliev [53] reported that animals treated with selective endothelial NO synthase (eNOS) inhibitors experienced increased cerebral edema during cerebral hypoperfusion, suggesting that eNOS-derived NO plays a critical role in the maintenance of cerebral blood flow and justifying the administration of NO donors.

Interestingly, in a study by Greco [54], pretreatment with the selective eNOS inhibitor, L-N-(1-iminoethyl)ornithine, at doses high enough to induce ischemic brain damage caused a significant reduction of the $\mathrm{I} \kappa \mathrm{B}$-alpha expression in the ischemic cortex, suggesting that eNOS-derived NO can prevent ischemic damage by inhibiting NF- $\kappa \mathrm{B}$ [47].

The activation of NF- $\kappa \mathrm{B}$ plays dual roles in cells death and survival, depending on the cell type, developmental stage, and apoptotic stimuli [55]. In normals cells, NF- $\kappa \mathrm{B}$ 
is associated with inhibitory $\mathrm{I} \kappa \mathrm{B}$ proteins that inhibit nuclear localization and DNA binding of NF- $\kappa \mathrm{B}$. In response to stimuli, including free radicals, which have been implicated in the pathogenesis of cerebral ischemia, $\mathrm{I} \kappa \mathrm{Bs}$ are phosphorylated by the $\mathrm{I} \kappa \mathrm{B}$ kinase, and subsequently degraded, releasing $\mathrm{NF}-\kappa \mathrm{B}$ to translocate into the nucleus where it binds to a $\kappa \mathrm{B}$-specific DNA motif and regulates transcription of target genes, including immunological NOS (iNOS), which are known to be induced in cerebral ischemia and capable of mediating the deleterious effect [56, 57]. Moreover, $\mathrm{NF}-\kappa \mathrm{B}$ is activated at earlier reperfusion time points and that early NF- $\kappa \mathrm{B}$ inhibition in transient focal ischemia has a beneficial effect [58].

In this study, when a NO donor (Rut-bpy) was administered prior to ischemia/reperfusion the expression of activated $\mathrm{NF}-\kappa \mathrm{B}$ was reduced in the hippocampal regions $\mathrm{Ca} 1$, $\mathrm{Ca} 2$ and $\mathrm{Ca} 3$, suggesting that Rut-bpy inhibited $\mathrm{NF}-\kappa \mathrm{B}$, probably through NO release from the ruthenium-nitrosyl complex. Further studies are required to evaluate the upstream cytokine network involved in this protective mechanism.

Paradoxically, but not uncommonly, when the blood flow is restored from ischemia, and viable brain cells and tissues are reoxygenated, free radicals tend to rise in neuronal, endothelial and glial cell environment [59, 60] leading to faster and farther cell damage, producing the socalled ischemia/reperfusion lesion.

Some free radicals are derived from NO produced by neuronal or immunological NOS (nNOS and iNOS, respectively), which form highly reactive peroxynitrite, responsible for cell membrane lipid peroxidation [61], including mitochondrial membranes. Noteworthy is that, the administration of the NO donor Rut-bpy may not cause significant lipid peroxidation, since pharmacologically increases in NO levels reported in several studies fail to exacerbate free radical production $[11,37]$ and because the mechanisms of neuronal protection during events of ischemia and reperfusion necessarily involve both NO production and NOS inhibition.

In addition, in animals receiving Rut-bpy, blood pressure (BP) was more stable during reperfusion and during the transition from ischemia to reperfusion. Increased BP stability may have enhanced the protective effect of Rutbpy administration, but more studies are needed to test the possible association between BP stability and cerebral damage in Rut-bpy pretreatment models.

In conclusion, when used in vivo, preconditioning with NO donor Rut-bpy was found to improved the total brain infarction area and hippocampal neuronal viability, in an early phase of ischemia/reperfusion, in part by inhibiting $\mathrm{NF}-\kappa \mathrm{B}$ signaling and helped to stabilize the blood pressure during the transition from ischemia to reperfusion. It may therefore be considered an attractive candidate for further investigation using experimental stroke models.

Acknowledgments $\mathrm{We}$ are in debt to $\mathrm{PhD}$. Prof. Renata $\mathrm{F}$. C. Leitão, Rossângela Barreto, Antônio Haroldo Pinheiro Ferreira, and Maria Silvandira França Pinheiro for their helpful technical assistance. $\mathrm{CNPq}$ and FUNCAP scholarships and research grants supported this work.

Conflict of interest There are no actual or potential conflicts of interests.

\section{References}

1. Kung HC, Hoyert DL, Xu J, Murphy SL (2008) Deaths: final data for 2005. National Vital Statistics Reports 56:1-120

2. Dawson VL, Dawson TM (1998) Nitric oxide in neurodegeneration. Prog Brain Res 118:215-229

3. Dawson VL, Dawson TM (1995) Physiological and toxicological actions of nitric oxide in the central nervous system. Adv Pharmacol 34:323-342

4. Willmot M, Gibson C, Gray L, Murphy S, Bath P (2005) Nitric oxide synthase inhibitors in experimental ischemic stroke and their effects on infarct size and cerebral blood flow: a systematic review. Free Radic Biol Med 39:412-425

5. Ignarro LJ, Buga GM, Wood KS, Byrns RE, Chaudhuri G (1987) Endothelium-derived relaxing factor produced and released from artery and vein is nitric oxide. Proc Natl Acad Sci USA 84:9265-9269

6. Dimmeler S, Haendeler J, Nehls M, Zeiher AM (1997) Suppression of apoptosis by nitric oxide via inhibition of interleukin$1 \mathrm{~b}$-converting enzyme (ICE)-like and cysteine protease protein (CPP)-32-like proteases. J Exp Med 185:601-607

7. Rossig L, Haendeler J, Hermann C et al (2000) Nitric oxide down-regulates MKP-3 mRNA levels: involvement in endothelial cell protection from apoptosis. J Biol Chem 275:25502-25507

8. Zhuang P, Ji H, Zhang YH, Min ZL, Ni QG, You R (2010) ZJM-289, a Novel nitric oxide donor, alleviates the cerebral ischemic-reperfusion injury in rats. Clin Exp Pharmacol Physiol 37:e121-e127

9. Ignarro LJ, Cirino G, Casini A, Napoli C (1999) Nitric oxide as a signaling molecule in the vascular system: an overview. J Cardiovasc Pharmacol 34:879-886

10. Ignarro LJ, Napoli C, Loscalzo J (2002) Nitric oxide donors and cardiovascular agents modulating the bioactivity of nitric oxide: an overview. Circ Res 90:21-28

11. Wainwright MS, Grundhoefer D, Sharma S, Black SM (2007) A nitric oxide donor reduces brain injury and enhances recovery of cerebral blood flow after hypoxia-ischemia in the newborn rat. Neurosci Lett 415:124-129

12. Khan M, Jatana M, Elango C, Paintlia AS, Singh AK, Singh I (2006) Cerebrovascular protection by various nitric oxide donors in rats after experimental stroke. Nitric Oxide 15:114-124

13. Zhang R, Zhang L, Zhang Z, Wang Y, Lu M, Lapointe M, Chopp M (2001) A nitric oxide donor induces neurogenesis and reduces functional deficits after stroke in rats. Ann Neurol 50:602-611

14. Silva FON, Araujo SXB, Holanda AKM, Meyer E, Sales FAM, Diogenes ICN, Carvalho IMM, Moreira IS, Lopes LGF (2006) Synthesis, Characterization, and NO Release Study of the cis- and trans-[Ru(Bpy)2(SO3)(NO)]+ complexes Eur J Inorg Chem 2020-2026 
15. Fricker SP, Slade E, Powell NA, Vaughan OJ, Henderson GR, Murrer BA et al (1997) Ruthenium complexes as nitric oxide scavengers: a potential therapeutic approach to nitric oxidemediated diseases. Br J Pharmacol 122:1441-1449

16. Hutchings SR, Song D, Fricker SP, Pang CC (2005) The ruthenium-based nitric oxide scavenger, AMD6221, augments cardiovascular responsiveness to noradrenaline in rats with streptozotocin-induced diabetes. Eur J Pharmacol 528:132-136

17. Silva JJN, Guedes PMM, Zottis A, Balliano TL, Silva FON, Lopes LGF, Ellena J, Oliva G, Andricopulo AD, Franco DW, Silva JS (2010) Novel ruthenium complexes as potential drugs for Chagas's disease: enzyme inhibition and in vitro/in vivo trypanocidal activity. Br J Pharmacol 160:260-269

18. Cerqueira JB, Silva LF, Lopes LG, Moraes ME, Nascimento NR (2008) Relaxation of rabbit corpus cavernosum smooth muscle and aortic vascular endothelium induced by new nitric oxide donor substances of the nitrosyl-ruthenium complex. Int Braz $\mathbf{J}$ Urol 34:638-646

19. Silva FO, Cândido MC, Holanda AK, Diógenes IC, Sousa EH, Lopes LG (2011) Mechanism and biological implications of the NO release of cis-[Ru(bpy) $2 \mathrm{~L}(\mathrm{NO})]^{\mathrm{n}+}$ complexes: a key role of physiological thiols. J Inorg Biochem 105:624-629

20. Bonaventura D, de Lima RG, Vercesi JA, da Silva RS, Bendhack LM (2007) Comparison of the mechanisms underlying the relaxation induced by two nitric oxide donors: sodium nitroprusside and a new ruthenium complex. Vascul Pharmaco $46: 215-222$

21. Muniz LRF, Faria MHG, Vasconcelos PRL (2004) Metabolic evaluation of ischemic and reperfusion brain injury following bilateral occlusion of common carotid arteries: an experimental study in rats. Acta Cir Bras 19:529-534

22. Ibayashi S, Nagao T, Kitazono T, Ooboshi H, Kitayama J, Sadoshima S, Fujishima M (2000) Calcium antagonist is radipine reduces metabolic alterations in acute cerebral ischemia in spontaneously hypertensive rats. Neurochem Res 25:349-355

23. Li Z, Wang Y, Xie Y, Yang Z, Zhang T (2011) Protective effects of exogenous hydrogen sulfide on neurons of hippocampus in a rat model of brain ischemia. Neurochem Res 36:1840-1849

24. Paxinos G, Watson C (2004) The rat brain in stereotaxic coordinates, 5th edn. Elsevier Academic Press, Burlington

25. Joshi CN, Jain SK, Murthy PS (2004) An optimized triphenyltetrazolium chloride method for identification of cerebral infarcts. Brain Res Brain Res Protoc 13:11-17

26. Bederson JB, Pitts LH, Germano SM, Nishimura MC, Davis RL, Bartkowski HM (1986) Evaluation of 2,3,5-triphenyltetrazolium chloride as a stain for detection and quantification of experimental cerebral infarction in rats. Stroke 17:1304-1308

27. Benedek A, Moricz K, Juranyi Z, Gigler G, Levay G, Harsing LG Jr et al (2006) Use of TTC staining for the evaluation of tissue injury in the early phases of reperfusion after focal cerebral ischemia in rats. Brain Res 1116:159-165

28. Isayama K, Pitts LH, Nishimura MC (1991) Evaluation of 2, 3, 5-triphenyltetrazolium chloride staining to delineate rat brain infarcts. Stroke 22:1394-1398

29. Leinonen JS, Ahonen JP, Lonnrot K, Jehkonen M, Dastidar P, Molnar G, Alho H (2000) Low plasma antioxidant activity is associated with high lesion volume and neurological impairment in stroke. Stroke 31:33-39

30. Goldlust EJ, Paczynski RP, He YY, Hsu CY, Goldberg MP (1996) Automated measurement of infarct size with scanned images of triphenyltetrazolium chloride-stained rat brains. Stroke 27:1657-1662

31. Kaku Y, Yonekawa Y, Tsukahara T, Ogata N, Kimura T, Taniguchi T (1993) Alterations of a $200 \mathrm{kDa}$ Neurofilament in the Rat Hippocampus after Forebrain Ischemia. J Cereb Blood Flow Metab 13:402-408
32. Green LC, Wagner DA, Glogowski J (1982) Analysis of nitrate, nitrite, and $[15 \mathrm{~N}]$ nitrate in biological fluids. Anal Biochem 126:131-138

33. Irmak MK, Fadillioglu E, Sogut S, Erdogan H, Gulec M, Ozer M, Yagmurca M, Gozukara ME (2003) Effects of caffeic acid phenethyl ester and alpha-tocopherol on reperfusion injury in rat brain. Cell Biochem Funct 21:283-289

34. Dirnagl U, Iadecola C, Moskowitz MA (1999) Pathobiology of ischaemic stroke: an integrated view. Trends Neurosci 22: 391-397

35. Lo EH, Moskowitz MA, Jacobs TP (2005) Exciting, radical, suicidal: how brain cells die after stroke. Stroke 36:189-192

36. Prieto-Arribas R, Pascual-Garvi JM, González-Llanos F, Roda JM (2011) How to repair an ischemic brain injury? Value of experimental models in search of answers. Neurologia 26:65-73

37. Pluta RM, Rak R, Wink DA, Woodward JJ, Khaldi A, Oldfield EH, Watson JC (2001) Effects of nitric oxide on reactive oxygen species production and infarction size after brain reperfusion injury. Neurosurgery 48:884-892

38. Zhang D, Dhillon HS, Mattson MP, Yurek DM, Prasad RM (1999) Immunohistochemical detection of the lipid peroxidation product 4-hydroxynonenal after experimental brain injury in the rat. Neurosci Lett 272:57-61

39. Gaur V, Kumar A (2010) Protective effect of desipramine, venlafaxine and trazodone against experimental animal model of transient global ischemia: possible involvement of NO-cGMP pathway. Brain Res 1353:204-212

40. Buisson A, Plotkine M, Boulu RG (1992) The neuroprotective effect of a nitric oxide inhibitor in a rat model of focal cerebral ischaemia. Br J Pharmacol 106:766-767

41. Lei H, Grinberg O, Nwaigwe CI, Hou HG, Williams H, Swartz HM, Dunn JF (2001) The effects of ketamine-xylazine anesthesia on cerebral blood flow and oxygenation observed using nuclear magnetic resonance perfusion imaging and electron paramagnetic resonance oximetry. Brain Res 913:174-179

42. Stein AB, Tiwari S, Thomas P, Hunt G, Levent C, Stoddard MF, Tang XL, Bolli R, Dawn B (2007) Effects of anesthesia on echocardiographic assessment of left ventricular structure and function in rats. Basic Res Cardiol 102:28-41

43. Levine S (1960) Anoxic-ischemic encephalopathy in rats. Am J Pathol 36:1-17

44. Lipton P (1999) Ischemic cell death in brain neurons. Physiol Rev 79:1431-1568

45. He Z, Ibayashi S, Sugimori H, Fujii K, Sadoshima S, Fujishima M (1997) Age-related ischemia in the brain following bilateral carotid artery occlusion-collateral blood flow and brain metabolism. Neurochem Res 22:37-42

46. Glenner GG (1969) Tetrazolium salts. In: Lillie RD (ed) H.J. Con's biological stains. Williams and Wilkins, Baltimore, pp 154-162

47. Li F, Irie K, Anwer MS, Fisher M (1997) Delayed triphenyltetrazolium chloride staining remains useful for evaluating cerebral infarct volume in a rat stroke model. J Cereb Blood Flow Metab 17:1132-1135

48. Marshall RS, Lazar RM, Pile-Spellman J, Young WL, Duong DH, Joshi S, Ostapkovich N (2001) Recovery of brain function during induced cerebral hypoperfusion. Brain 124:1208-1217

49. Willmot MR, Bath PM (2003) The potential of nitric oxide therapeutics in stroke. Expert Opin Investig Drugs 12:455-470

50. Sanchez A, Fernandez N, Monge L, Salcedo A, Climent B, Luis Garcia-Villalon A, Diéquez G (2006) Goat cerebrovascular reactivity to ADP after ischemia-reperfusion. Role of nitric oxide, prostanoids and reactive oxygen species. Brain Res 1120: $114-123$

51. Wieraszkoa A, Clarkeb MJ, Langb DR, Lopes LGF, Franco DW (2001) The influence of NO-containing ruthenium complexes on 
mouse hippocampal evoked potentials in vitro. Life Sci 68:1535-1544

52. Tardini DMS, Winston BY, Novelli ELB, Sequeira JL (2003) Evaluation of two brain ischemia and reperfusion experimental models in rats with carotid temporary occlusion associated or not to vertebral occlusion. Acta Cir Bras 18:514-517

53. De La Torre JC, Aliev G (2005) Inhibition of vascular nitric oxide after rat chronic brain hypoperfusion: spatial memory and immunocytochemical changes. J Cereb Blood Flow Metab 25: 663-672

54. Greco R, Mangione AS, Amantea D, Bagetta G, Nappi G, Tassorelli C (2011) IkappaB-alpha expression following transient focal cerebral ischemia is modulated by nitric oxide. Brain Res 1372:145-151

55. Kaltschmidt B, Heinrich M, Kaltschmidt C (2002) Stimulusdependent activation of NF-kappaB specifies apoptosis or neuroprotection in cerebellar granule cells. Neuromolecular Med 2:299-309

56. Medling BD, Bueno R, Chambers C, Neumeister MW (2010) The effect of vitamin $\mathrm{E}$ succinate on ischemia reperfusion injury. Hand 5:60-64
57. Wang Q, Tang XN, Yenari MA (2007) The inflammatory response in stroke. J Neuroimmunol 184:53-68

58. Desai A, Singh N, Raghubir R (2010) Neuroprotective potential of the NF- $\kappa$ B inhibitor peptide IKK-NBD in cerebralischemiareperfusion injury. Neurochem Int 57:876-883

59. Lefer AM, Lefer DJ (1993) Pharmacology of the endothelium in ischemia-reperfusion and circulatory shock. Annu Rev Pharmacol Toxicol 33:71-90

60. Thiagarajan RR, Winn RK, Harlan JM (1997) The role of leukocyte and endothelial adhesion molecules in ischemia-reperfusion injury. Thromb Haemost 78:310-314

61. Goto S, Xue R, Sugo N, Sawada M, Blizzard KK, Poitras MF, Johns DC, Dawson TM, Dawson VL, Crain BJ, Traystman RJ, Mori S, Hurn PD (2002) Poly(ADP-ribose) polymerase impairs early and long-term experimental stroke recovery. Stroke 33: $1101-1106$ 